\title{
Nominal mismatches in Swahili locatives
}

\author{
Soo-Hwan Lee \& Doo-Won Lee*
}

\begin{abstract}
According to Carstens (2008), Bantu locatives in general project double DPs. However, recent works have presented convincing evidence for a reduction in nominal size for Bantu locatives (Fuchs \& van der Wal 2017, 2018). We argue that the actual size of nominals in Swahili, a language of the Bantu family, depends on the type of locative expression. In this regard, a mismatch in terms of nominal size is observed for Swahili. By means of analyzing such mismatch, we adopt the PP analysis as well as the stacked- $n$ analysis suggested by Kramer (2015). In doing so, we demonstrate that there are two distinct ways of forming Swahili locatives. The first is to utilize a prepositional head, P (e.g., $k w a)$, projected above a full nominal whereas the other is to make use of the head, $n$ (e.g., $-n i)$, projected within a reduced nominal. Such dissimilarity in constructing locatives, in turn, gives rise to mismatches in Swahili nominals.
\end{abstract}

Keywords. Swahili; locatives; gender; bare nominals; stacked- $n$ analysis

1. Introduction. This work mainly investigates noun phrases and reduced nominal expressions in Swahili locatives which somehow lack in syntactic structure. By means of analyzing reduced nominal expressions in greater detail, this work adopts a cross-linguistic approach on viewing the hierarchical system of nominal domains as follows:

$$
\mathrm{PP}>\mathrm{KP}>\mathrm{DP}>\# \mathrm{P}>n \mathrm{P}>\mathrm{NP}
$$

With a full nominal expression being KPs, (reduced) nominal expressions such as DPs, \#Ps, $n$ Ps, and NPs may be realized depending on the given language and the ways in which the nominals are structurally organized. With regards to these small nominal expressions, we demonstrate that Swahili locatives can be realized without the presence of PPs or DPs. Further, we claim that these locatives are realized in an $n \mathrm{P}$ hosting the locative morpheme, $n i$. By eliminating the upper layers, namely PPs and DPs, deriving a reduced nominal for Swahili locatives is possible which shares similarities with the English bare nominal locatives (see Barrie \& Yoo 2017). Hence, this work primarily investigates how a bare $n$ P consisting of the locative morpheme, -ni, satisfies the realization of locatives in Swahili.

2. English Locatives. Prior to scrutinizing the realization of reduced nominals in Swahili, let us first consider English locatives which may either be projected within a PP or a bare NP mentioned by Barrie \& Yoo (2017).

a. John ate the apple *(in) the kitchen.

b. John lives *(in) that place.

a. The place that John lives (in) is expensive.

b. Mary has lived (in) many places.

As far as (2) is concerned, the presence of a PP is obligatory, since the absence of it clearly

\footnotetext{
* We thank Michael Barrie for providing us the opportunity to work on Bantu languages. We also express our great appreciation to the audiences at SICOGG20 and the 93rd Annual Meeting of the Linguistic Society of America for their helpful comments. This work was supported by CORE (College of Humanities' Research and Education) and the Global Research Network program funded by the Ministry of Education of the Republic of Korea and the National Research Foundation of Korea (NRF-2017S1 A2A2039972). Any remining errors are our own. Authors: Soo-Hwan Lee, Sogang University (soohwanlee@sogang.ac.kr) Doo-Won Lee, Korea National University of Transportation (dwlee@ut.ac.kr).
} 
devastates the grammaticality of (2a) and (2b). Quite dissimilarly, (3) speaks in favor of the optionality of PPs. According to Barrie \& Yoo (2017), the fundamental difference between (2) and (3) derives from the notion that the former comprises of a PP and a DP, which requires Case from the PP. This, in turn, suggests that the elimination of the PP violates the requirement on the Case marking for the DP. However, this is not the case for (3) where the nominal, place, may project a bare NP which is not in need of a Case. Furthermore, the bare NP in (3) is lexically prespecified with a $\theta$-role which does not require an overt $\theta$-assigner. Thus, the absence of a PP as well as a DP is possible on Barrie \& Yoo's (2017) account.

3. Swahili Locatives. In the Eastern Bantu language, Swahili, there are two ways of forming locatives from a morphosyntactic point of view. The first is to utilize a prepositional head, $\mathrm{P}$, projected above a full nominal such as a DP whereas the other is to make use of the head, $n$, projected within a nominal structure. In order to verify such notion in greater detail, the Swahili nominals realized with the locative inducing elements, $k w a$ and $n i$, will be introduced in the following subsections.

3.1. SWAHILI LOCATIVES WITH $K W A$. Similar to (2) in which the Case assigner, PP, must participate in constructing locatives in English, locatives in Swahili used with the prepositional head, $k w a$, is in need of a full DP which requires a Case assigner as well as a $\theta$ assigner situated beyond the scope of a full nominal domain. Consider the following data:
a. Juma hu-penda ku-lala
Juma 3.sg-like INF-sleep
*(kwa) nyumba hii
'Juma likes to sleep in this house.'
b. Juma hu-penda ku-lala
LOC house this
Juma 3.sg-like INF-sleep
*(kwa) nyumba mbili
'Juma likes to sleep in two houses.'
LOC house two

In (4), the realization of a PP is obligatory because the head, P, must be filled in by the locative element, $k w a$. Additionally, the evidence that a full DP is in sister relation with the prepositional head, $k w a$, is illustrated in (4a) where the demonstrative, hii 'this', is able to appear with $k w a$. Following the analysis of Universal merge order of 'Dem $>$ Numeral $>$ Adjective $>$ N' (Cinque 2000, 2005), this work suggests that the locative structures in (4a) and $(4 \mathrm{~b})$ undergo movement as demonstrated below:

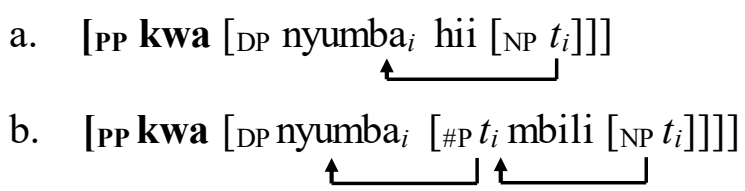

Quite significantly, the realization of $k w a$ with a conjunction connecting two different DP structures is a clear evidence that the locative element, $k w a$, truly exhausts the prepositional head, P, of a PP situated beyond the scope of a DP. Consider the following data:
a. Juma a-li-ishi kwa nyumba hii Juma 3.sg-PST-live LOC house this na kwa nyumba ile 'Juma lived in this house and in that house.'
b. Juma a-li-ishi kwa nyumba hii Juma 3.sg-PST-live LOC house this 'Juma lived in this house and that house.'
na nyumba ile
CONJ house that
CONJ LOC house that

The conjunction, $n a$ 'and', in (6a) and (6b) respectively conjoins a PP with a PP (e.g., [PP kwa [DP nyumba hii]] with [PP kwa [DP nyumba ile]]) and a DP with a DP (e.g., [DP nyumba hii] with [DP nyumba ile]). This, once again, works in favor of the notion that a prepositional head 
led by $k w a$ attaches onto a DP (or DPs), crucially because the conjunction, namely $n a$, in (6b) structurally intervenes between a $\mathrm{P}, k w a$, and the two full nominal expressions, namely nyumba hii and nyumba ile. Further significance of the data will come to light in the following subsection where the locative indicating morpheme, $n i$, is used with the same conjunction displaying a structural pattern dissimilar to that of kwa. (7) illustrates the structures for PPs and DPs which are realized with the conjunction, $n a$, in (6a) and (6b).

a. $n a$ connecting two PPs in (6a)

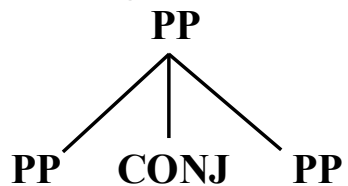

[[kwa nyumba hii] na [kwa nyumba ile $]]$ b. $n a$ connecting two DPs in (6b)

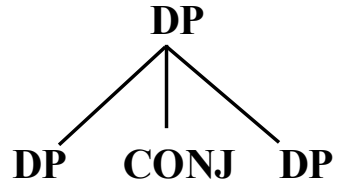

[[nyumba hii] na [nyumba ile]]

According to (7b) in particular, the extraction of $k w a$ takes place across the board (ATB), since $k w a$ is a preposition which is independent from nominal-internal structures such as $n$ Ps. In this regard, syntactic partitioning is made possible as long as a conjunction (e.g., na in (7)) connects and projects DPs. Following this string of logic, PPs may properly adjoin to wellformed DP structures such as nyumba hii and nyumba ile.

3.2. SWAHILI LOCATIVES WITH NI. Having established that certain Swahili locatives require PPs and DPs, we now direct our attention towards an alternative way of forming locatives in Swahili via the locative-engendering morpheme, $n i$, which clearly patterns differently from the prepositional head, $k w a$.

$\begin{array}{lllll}\text { a. Juma hu-penda ku-lala } & \text { nyumba *(ni) } & \\ \text { Juma 3.sg-like INF-sleep } & \text { house LOC } & \\ \text { 'Juma likes to sleep in the house.' } & & & \\ \text { b. Juma hu-penda ku-lala } & \text { nyumba ni } & \text { (*hii) } \\ \text { Juma 3.sg-like INF-sleep } & \text { house LOC } & \text { this } \\ & \text { Intended: 'Juma likes to sleep in this house.' } & \\ \text { c. Juma hu-penda ku-lala } & \text { nyumba ni } & \text { (*mbili) } \\ \text { Juma 3.sg-like INF-sleep } & \text { house LOC } & \text { two } \\ \text { Intended: 'Juma likes to sleep in two houses.' } & \end{array}$

As depicted in (8), the locative morpheme, $n i$, is realized only with a bare nominal such as nyumba 'house' which surfaces without demonstratives (e.g., hii) and numerals (e.g., mbili) uninflected to the locative gender classes of 16,17 , and 18 . Here, the realization of the locative classes 16, 17, and 18 within Swahili (minor) gender system is attributed to the existence of $n$ Ps following Kramer's (2016) analysis. Moreover, the co-existential invalidity of the prepositional head, $k w a$, and the locative element, $n i$, directs us toward the notion that PPs cannot be projected over nominal structures bearing $n i .^{1}$ At this point, a clear distinction

1 The possibility of treating $n i$ as a regular Case marker instead of a preposition may seem plausible at first glance. However, the fact that the suffix-like locative element, $n i$, always follows a nominal expression without a demonstrative (D) or a numeral (\#) dismisses such prediction. Consider the following ill-formed structures where $n i$ is detached from nyumba 'house', due to an intervening DP:

(i)

$\begin{array}{lllll}\text { *Juma hu-penda } & \text { ku-lala } & \text { nyumba hii } & \text { ni } \\ \text { Juma } & \text { 3.sg-like INF-sleep } & \text { house } & \text { this } & \text { LOC } \\ \text { Intended: 'Juma likes to sleep in this house.' } & & \\ \text { *Juma hu-penda } & \text { ku-lala } & \text { nyumba } & \text { mbili } & \text { ni } \\ \text { Juma 3.sg-like INF-sleep house } & \text { two } & \text { LOC } \\ \text { Intended: 'Juma likes to sleep in two houses.' } & & \end{array}$


between the bare NPs used for English locatives and the bare nominals (e.g., nyumba-ni 'in the house') in Swahili locatives comes to light when we realize that only the latter hosts an overt locative-inducing morpheme. In accordance with such observation, the level of $n i$-type locatives in Swahili elevates to the nominal layer, $n \mathrm{P}$, instead of the bare NP. This is in accordance with the hierarchical system of nominal projections aforementioned in (1). Since demonstratives (e.g., hii) and prepositions (e.g., $k w a$ ) in Swahili are generated well beyond the scope of an $n \mathrm{P}$, postulating a bare $n \mathrm{P}$ structure for the $n i$-type locatives effectively explains the incapability of stacking additional projections such as DPs or PPs. (9b) demonstrates the unavailability of head movement up to the syntactic head, D.

$$
\begin{aligned}
& \text { a. } \quad{ }_{n \mathrm{P}} \text { nyumba }_{i} \text { ni }\left[\mathrm{NP} t_{i}\right] \\
& \text { b. (*[PP [DP hii) }\left[{ }_{n \mathrm{P}}\right. \text { nyumba }
\end{aligned}
$$

[invalid NP-raising in (8b)]

Returning to the usage of conjunctions, we see a mismatch between $n i$ and the prepositional head, $k w a$, when $n a$ 'and' tries to conjoin two bare $n$ Ps. The co-existential incompatibility of the locative element, $n i$, with the conjunction, $n a$, is a supporting evidence that the locative element, $n i$, does not exhaust a prepositional head, $\mathrm{P}$, but a head internal to a nominal smaller than a DP. Consider the following data which is inconsistent with the structural pattern shown in (6):

$$
\begin{aligned}
& \text { a. 'Juma a-li-ishi } \text { nyumba ni hii na nyumba ni ile } \\
& \text { Juma 3rd.sg-PST-live house LOC this CONJ house LOC that } \\
& \text { 'Juma lived in this house and in that house.' } \\
& \text { b. 'Juma a-li-ishi nymba hii na nyumba ile ni } \\
& \text { Juma 3rd.sg-PST-live house this CONJ house that LOC } \\
& \text { 'Juma lived in this house and that house.' }
\end{aligned}
$$

The conjunction, $n a$ 'and', in (10a) as well as (10b) is unable to conjoin a PP with a PP (e.g.,

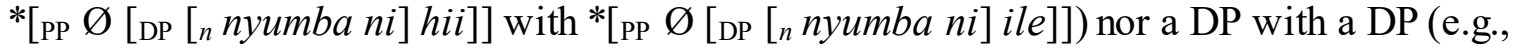

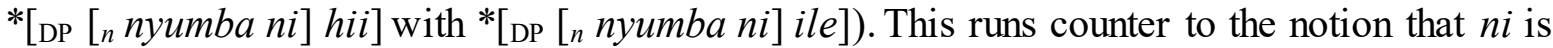
a prepositional head hosting a DP (or DPs), since $n a$ in (10b) is unable to connect two full DPs in the absence of a PP. In other words, the absence of a PP for $n i$ devastates the derivation of a coordinating conjunction hoping to connect two full-fledged nominal expressions. $^{2}$ This, in turn, suggests that the locative element, $n i$, is reduced in size and that it specifically lacks a DP and most certainly a PP. Through such findings, we argue that Swahili is able to form locatives without the need of a PP since making use of the locative-inducing projection, $n \mathrm{P}$, is possible. In this regard, $n i$-type locatives ought to be distinguished from $k w a$-type locatives which surface beyond the level of a nominal domain. The following data illustrates the invalidity of postulating PPs or DPs for the $n i$-type locatives in Swahili.

\footnotetext{
According to (i) and (ii), $n i$ has to be realized closely adjacent to a bare or a reduced nominal which is not necessarily a characteristic of a KP or a DP. Further discussion will continue in section 5 which presents additional data relevant to Korean locatives.

${ }^{2}$ In fact, $n i$-type locatives are unable to conjoin two different nominals even when demonstratives are not present.
}

$$
\begin{aligned}
& \text { *shule na nyumba ni } \\
& \text { school CONJ house LOC } \\
& \text { Intended: 'in the school and the house' }
\end{aligned}
$$

(iii) shows that the locative head, $n i$, is not separable from its nominal expression. This shares commonalities with inherent gender features immediately attached onto nominal roots. 

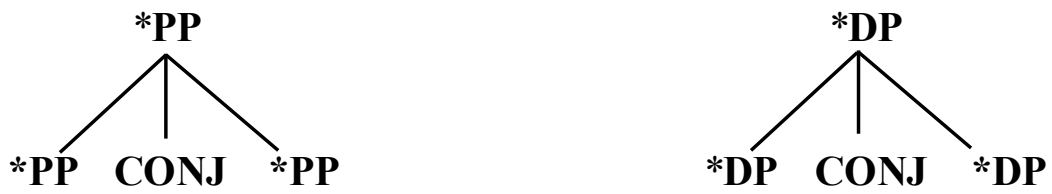

$*\left[\left[\varnothing_{\mathrm{P}}\right.\right.$ nyumba-ni hii $]$ na $\left[\emptyset_{\mathrm{P}}\right.$ nyumba-ni ile $\left.]\right] *[[$ nyumba-ni hii $]$ na [nyumba-ni ile $\left.]\right]$

Here, it is crucial to note that the extraction of $n i$ cannot take place across the board (ATB) since it is an element trapped inside a nominal domain smaller than a DP. Hence, a form of syntactic partitioning is not possible which is in stark contrast to what we saw for locative structures holding onto the prepositional head, $k w a$, illustrated in (7).

\section{Different morphosyntactic structures for $\boldsymbol{k w a}$ and $\boldsymbol{n i}$. As for Case and $\theta$-role} assignments, a reduced $n \mathrm{P}$ does not require Case for it is not a full-blown DP. Moreover, assigning $\theta$-roles to $n \mathrm{Ps}$ is unproblematic since assigning it is possible through the nominal head, $n_{\mathrm{LOC}}{ }^{\circ}$, undergoing (rich) agreement in Bantu languages (Carstens 2008). In fact, Fuchs $\&$ van der Wal (2018) presents a stacked- $n$ analysis for Swahili locatives which is in line with what Kramer (2015) suggests for German nominalization (e.g., lerherin 'female teacher'). While the stacked- $n$ analysis may be applicable to the $n i$-type locatives in Swahili, I argue that such analysis should not be introduced for the kwa-type locatives. Otherwise, the given logic would wrongly predict the coexistence of two locative heads, namely $\mathrm{P}_{\mathrm{LOC}}$ as well as $n_{\text {LOC }}$ (e.g., $* k w a$ nyumba-ni), which eventually leads to a crash in derivation. Consider the follow structure:

\section{*kwa nyumba-ni}

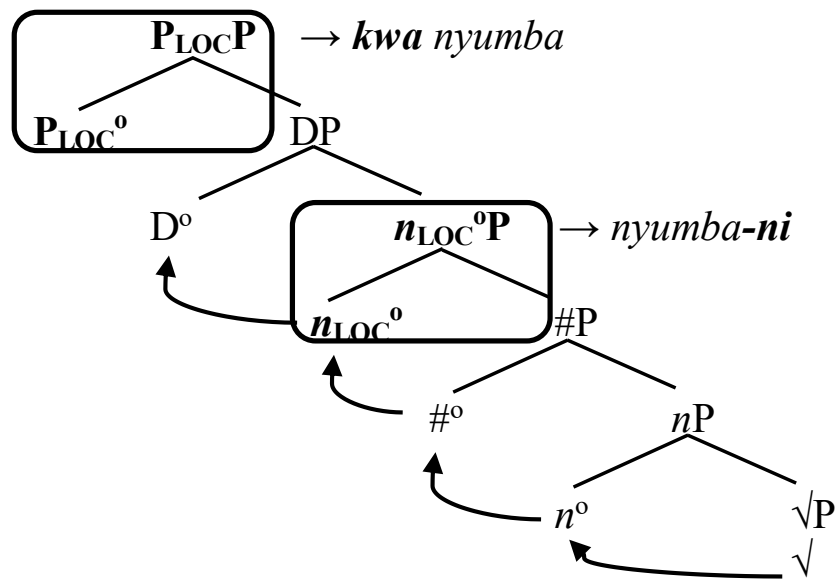

As illustrated in (12), the coexistence of two locative-inducing heads, $\mathrm{P}_{\mathrm{LOC}}{ }^{\circ}$ and $n_{\mathrm{LOC}}{ }^{\mathrm{o}}$, is invalidated as we observed that *kwa nyumba-ni is ill-formed from a derivational account. Hence, only the cases where either one of the given heads is present for each and every derivation may be well-formed. The implication for such analysis would be that Swahili locatives formed under the prepositional head, $\mathrm{P}_{\mathrm{LOC}^{\circ}}{ }^{\circ}$ (e.g., $k w a$ ), carry a full nominal expression such as a DP while the locatives formed under the nominal-internal head, $n_{\mathrm{LOC}}{ }^{\circ}$ (e.g., $n i$ ), would be in no explicit need of a full-blown nominal construction. This certainly touches on some of the previously overlooked phenomena in Swahili and it also leaves Carstens' (2008) assumption on projecting double DPs unwarranted. From what is presented in (12), we can put forward the assumption that gender inflection itself introduces locatives. The dissimilar tree structures under which kwa nyumba and nyumba-ni are realized nicely portray the main points discussed so far: 


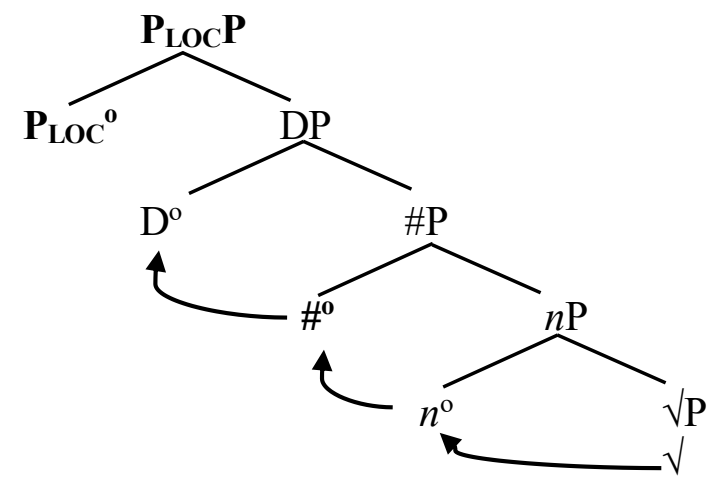

b. nyumba-ni (a reduced nominal)

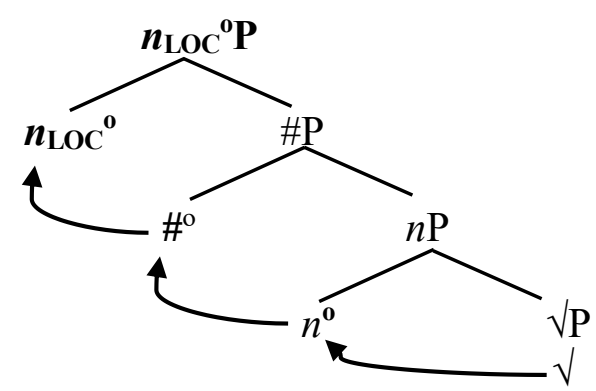

In addition, arguing for a stacked- $n$ analysis for Bantu languages in general gains good support when adopting Kramer's (2015) and Fuchs \& van der Wal's (2018) line of reasoning. Surely, the realization of nominal locatives in Bemba reassures the plausibility of postulating a stacked $n \mathrm{P}$ from a cross-linguistic perspective. Consider the following data which holds onto a prototypical nominal locative system in Bantu:

a. Locative gender classes 16, 17, and 18 (Adopted from Carstens 2008)

\begin{tabular}{|c|c|c|}
\hline Noun class & Example & Gloss \\
\hline $16($ LOC) & noun +16 & specific place \\
\hline $17($ LOC) & noun +17 & general place \\
\hline $18($ LOC) & noun +18 & inside place \\
\hline
\end{tabular}

b.

$\begin{array}{lll}\text { pa-n-gándá } & \text { c. } & \text { kú-n-gándá } \\ \text { 16-9-house } & & \begin{array}{l}\text { 17-9-house } \\ \text { 'at the house' }\end{array}\end{array}$

d. mu-n-gándá

18-9-house

'in the house'

(Bemba, Marten 2012)

Undoubtedly, the use of gender morphemes belonging to the classes of 16 (e.g., pa), 17 (e.g., $\left.k u^{\prime}\right)$, and 18 (e.g., $m u$ ) in order to create locatives is quite common in prototypical Bantu languages. Hence, as shown in (14b), stacking an additional gender component categorized under classes 16,17, and 18 to a preexisting gender element such as class 9 (e.g., $n$ ) is also valid when forming locatives in Bantu languages such as Bemba. In light of such analysis, adding a locative-engendering feature above an initial gender element via $n_{\text {LOC }}{ }^{\circ}$ brings no apparent complication to the story (see Fuchs \& van der Wal (2018) for further discussion). Here, it is significant to understand that the locative genders used in Bantu languages help account for the morphosyntactic characteristics of Swahili $n i$-type locatives as striking similarities between the two are observed. Consider the following data on Cuwabo which is able to utilize both a prefix as well as a suffix locative system in Bantu: 


$$
\begin{aligned}
& \text { a. va-mú-rî-ni } \quad \text { b. ó-ttóló-ni } \quad \text { c. } \quad \text { m-mú-rúddá-ni } \\
& \text { 16-3-tree-LOC 17-well-LOC 18-3-village-LOC } \\
& \text { 'at the tree' 'at the well' 'in the village' } \\
& \text { (Cuwabo, Guérois 2014, 2015) }
\end{aligned}
$$

As emphasized in (15), the double usage of classes 16 (e.g., va), 17 (e.g., ó), and 18 (e.g., $m$ ) along with the suffix-like $n i$ shows that the features are indeed closely related to one another. As a matter of fact, an explicit interaction between and among locative gender features is observed when the overt inflections triggered by the Swahili $n i$-type locatives are given consideration:

$$
\begin{array}{lll}
\text { nyumba-ni } & \text { pa-/ kú-/m-na wa-tu } & \text { w-engi } \\
\text { 9.house-LOC } & \mathbf{1 6}-/ \mathbf{1 7}-/ \mathbf{1 8} \text {-have 2-people } & \text { 2-many }
\end{array}
$$

'In/at the house are many people.'
a. nyumba-ni
pa-ngu
house-LOC
16-my
'at my house'
d. *nyumba-ni house-LOC
pa-hii/ile(pale) 16-this/that
b. nyumba-ni
kwa-ngu
house-LOC
17-my
'to my house'
c. nyumba-ni
mwa-ngu
house-LOC
'in my house'
18-my
e. *nyumba-ni kwa-hii/ile(kule) house-LOC 17-my
'to this/that house'
f. *nyumba-ni
house-LOC
'in this/that house'
mwa-hii/ile(mule)
18-my

The inflections triggered on $n a$ 'to have' in (16) and the possessive, $n g u$ 'my', in (17a), (17b), and $(17 \mathrm{c})$ direct us toward the notion that the locative-engendering element, $n i$, in Swahili certainly patterns with the prototypical locative gender classes of 16,17 , and 18 . In light of such discovery, it is more than plausible to assert that both of the affix-like locative elements are base-generated in the same nominal head of $n_{\mathrm{LOC}}{ }^{\mathrm{b}}$ which generates an identical effect on Bantu locative inflections. ${ }^{3}$ With this analysis at work, however, a question remains unsolved, since (17d), (17e), and (17f) remain ungrammatical despite their seemingly appropriate realizations. In order to capture the motivation for such mismatch in nominal patterns between $(17 \mathrm{a}-\mathrm{c})$ and $(17 \mathrm{~d}-\mathrm{f})$, this paper adopts Carstens (2008) way of treating possessives which is to say that they are components initially realized within $n$ Ps. This, in turn, suggests that possessives in Swahili are just one variety of $n$ which is distinct from demonstratives base-generated in DPs. Such morphosyntactic dissimilarity between possessives and demonstratives helps us account for the grammatical mismatch shown in (17). To put it in other words, the reduced nominals realized with $n i$-type locatives are able to introduce possessives situated in $n$ Ps (or \#Ps via nominal head movement) whereas demonstratives cannot be introduced owing to the notion that they are situated above and beyond the domain of $n$ Ps.

An unprecedentedness is added to the story when we realize that these nominal constructions rejected in Swahili are in fact readily available in Bemba, Cuwabo, and Chichewa.

\footnotetext{
3 Hankamer \& Mikkelsen (2018) argue that the identity of a prefix as well as a suffix is recognized during Vocabulary Insertion(VI) in the framework of Distributed Morphology (Halle \& Marantz 1993, 1994). Richards (2016) additionally mentions a way of identifying prefixes and suffixes by looking into the metrical boundaries initially detected in narrow syntax. We are in favor of these proposals and suggest that the placement(s) of the locative prefixes and suffixes in Bantu languages are predictable from a generative perspective.
} 


$$
\begin{aligned}
& \text { a. pà-mù-shí pà-lyá } \\
& \text { 16-3-village 16-DEM } \\
& \text { 'at that village' } \\
& \text { b. kù-mù-shí kù-lyá } \\
& \text { 17-3-village 17-DEM } \\
& \text { 'to that village' } \\
& \text { c. mù-mù-shí mù-lyà } \\
& \text { 18-3-village 18-DEM } \\
& \text { 'in that village' } \\
& \text { a. mu-papóóro-ni mpúle } \\
& \text { 18-1.boat-LOC 18.that } \\
& \text { 'into that boat' } \\
& \text { b. ku-nyumba 'ku } \\
& \text { 17-9.house 17.DEM } \\
& \text { 'that house' } \\
& \begin{array}{l}
\text { 'ku } \\
\text { 17.DEM }
\end{array}
\end{aligned}
$$$$
\text { (Bemba, Kula 2012) }
$$

(Cuwabo, Guérois 2016)

(Chichewa, Carstens 2008)

Here, the well-formedness of (18) and (19) is a crucial piece of evidence supporting the idea that Swahili $n i$-type locatives realized within $n_{\mathrm{LOC}}{ }^{\circ} \mathrm{Ps}$ are structurally primitive due to their lack of DPs. Unlike Bemba, Cuwabo, and Chichewa nominals compatible with demonstratives inflected to the locative gender classes of 16,17 , and 18, the reduced nominal locatives in Swahili are at odds with such entities because a full DP is absent. Hence, Bemba, Cuwabo, and Chichewa are able to freely build their nominal locatives using DPs, whereas Swahili nominal locatives cannot due to their restrictions on introducing demonstratives. ${ }^{4}$ In order to compensate for such loss, however, Swahili forms locatives with demonstratives using a different mechanism which has already been discussed in section 3. Such mechanism is once again repeated below:

$$
\begin{aligned}
& \text { a. Kwa nyumba hii } \\
& \text { LOC house this } \\
& \text { 'in this house' } \\
& \text { b. } \quad \text { kwa nyumba ile } \\
& \text { LOC house that } \\
& \text { 'in that house' }
\end{aligned}
$$

The proper way of expressing well-formed locative expressions bearing demonstratives in Swahili is through the use of a prepositional head (e.g., $k w a$ ) which is fully capable of summoning a DP. (20) shown above repeats the central ideas previously mentioned in (6) as well as (13) and reemphasizes the notion that Swahili demonstratives such as hii and ile demand a PP instead of an $n_{\mathrm{LOC}}{ }^{\circ} \mathrm{P}$. In fact, the analysis made thus far seems to account for Marten's (2010) observation on Swati, a Southern Bantu language. The locatives in Swati behave as preposition phrases instead of noun phrases. In addition to such discovery, I argue that Swahili is capable of utilizing both a propositional system as well as a reduced nominal system in terms of expressing locatives.

5. Additional evidence from Korean locatives. As opposed to Bantu languages assigning locatives through their nominal gender system(s), Korean adopts a system driven by Case

\footnotetext{
${ }^{4}$ It has been suggested by Carstens (2008) that possessives in Swahili are derived from $n$ Ps unlike demonstratives which are base-generated in DPs. In this regard, the reduced nominals that the $n i$-type locatives introduce are compatible with possessives and are not compatible with demonstratives since only the former lack a full-fledged DP.
} 
which cannot be analyzed using the stacked- $n$ demonstrated in (13b). Owing to its lack of $n_{\mathrm{LOC}}{ }^{\circ} \mathrm{P}$, Korean bears no possibility of introducing reduced nominal locatives which contrasts with Swahili (e.g., nyumba-ni) from a cross-linguistic point of view. Nevertheless, it is worth mentioning the fact that the coexistence of a locative Case as well as a demonstrative expression in Korean provides additional support to the claim that Swahili ni-type nominal locatives are truly dwindled in morphosyntactic size and structure.
a. Inwu-ka ku cip-ey Inwu-NOM that house-LOC 'Inwu went to that house.'
b. Inwu-ka i cip-eyse Inwu-NOM this house-LOC 'Inwu lived in this house.'

\author{
ka-ss-ta \\ go-PST-DECL \\ sal-ass-ta \\ live-PST-DECL
}

At any rate, the Case locatives, ey and-eyse, in (21) are arguably realized in KPs or DPs which are not in harmony with the Swahili $n_{\mathrm{LOC}}{ }^{\circ} \mathrm{P}$ locative element, $n i$. Evidence comes from the realization of ey and eyse used with demonstratives such as $i$ 'this' and $k u$ 'that' which are projected on the same or a lower domain posited for Case locatives in Korean. In contrast to Korean locatives, the $n_{\mathrm{LOC}}{ }^{\circ}$-type locatives in Swahili cannot host a demonstrative as we have already seen in (8), (10), and (17). This indicates that the realization of $n i$-type locatives cannot take place on a KP or a DP. Considering the discussion made up to this point, we have gained explicit motivations for arguing that the Swahili $n i$-type locatives and the Korean ey/eyse-type locatives are situated in different nominal layers and that the $n i$-type locatives are projected lower than KPs or DPs unlike their prepositional counterpart, kwa.

6. Conclusion. This work mainly investigated the morphosyntactic dissimilarities between the Swahili locatives, $k w a$ and $n i$. In the case of nominals formed under the realization of the prepositional head, $k w a$, a full-fledged DP is required since the preconditioning of the overt Case and $\theta$-role assigner/assignee relation ought to be satisfied similar to what we have observed for English locatives projecting complete nominal DPs. As for those that are realized with the locative morpheme, $n i$, neither a PP nor a full-blown DP is projected since there is no preconditioning of the overt Case and $\theta$-role assigner/assignee relation. Further support on this analysis derives from the complete absence of demonstratives (un)inflected by Swahili gender classes of 16,17 , and 18 when the locative engendering morpheme, $n i$, surfaces. This directs us toward the notion that $n i$-type locatives in Swahili are realized within a stacked $n \mathrm{P}$ layer which is somehow reduced in morphosyntactic size. With the attempt of collecting additional evidence verifying such reduction in size for Swahili locatives, we presented dissimilar patterns displayed in other Bantu languages such as Bemba, Cuwabo, and Chichewa. In the end, Swahili turned out to be the only language among the four to reject the usage of demonstratives with nominal locatives. As an alternative option, Swahili allowed $k w a$-type locatives to introduce demonstratives since they exhibit no reduction in form. As it has been predicted and postulated throughout this paper, the necessity of reduced nominal expressions for Swahili locatives comes to light when the $n i$-type locatives are given consideration from various morphosyntactic aspects.

\section{References}

Barrie, Michael \& Isaiah Yoo. 2017. Bare Nominal Adjuncts. Linguistic Inquiry 48(3). 499-512. https://doi.org/10.1162/ling a 00251.

Bobaljik, Jonathan David. 2000. The ins and outs of contextual allomorphy. University of Maryland working papers in linguistics 10. 35-71. 
Bobaljik, Jonathan David \& Uli Sauerland. 2018. *ABA and the combinatorics of morphological features. Glossa: A Journal of General Linguistics 3(1). https://doi.org/10.5334/gjgl.345.

Carstens, Viki. 1997. Empty nouns in Bantu locatives. The Linguistics Review 14. 361-410. https://doi.org/10.1515/tlir.1997.14.4.361.

Carstens, Viki. 2008. DP in Bantu and Romance. In Cécile De Cat \& Katherine Demuth (eds.), The Bantu-Romance Connection. 131-166. Amsterdam: John Benjamins. https://doi.org/10.1075/1a.131.10car.

Cinque, Guglielmo. 2000. On Greenberg's Universal 20 and the Semitic DP. In Laura Bruge (eds.), University of Venice Working Papers in Linguistics. 10(2). 45-61.

Cinque, Guglielmo. 2005. On deriving Greenberg's Universal 20. Linguistic Inquiry 36(3). 315-332. https://doi.org/10.1162/0024389054396917.

Deal, Amy Rose. 2016. Plural exponence in the Nez Perce DP: A DM analysis. Morphology 26(3-4). 313-339. https://doi.org/10.1007/s 11525-015-9277-9.

Fuchs, Zuzanna \& Jenneke van der Wal. 2018. Bantu DP structure: A little $n$ analysis of gender. Poster presented at the 92nd Annual Meeting of the LSA, Salt Lake City, UT.

Guérois, Rozenn. 2014. Locative inversion in Cuwabo. ZAS Papers in Linguistics 57. 49-71.

Guérois, Rozenn. 2015. A grammar of Cuwabo (Mozambique, Bantu P34). Ph.D. dissertation. Lyon: University of Lyon 2.

Guérois, Rozenn. 2016. The locative system in Cuwabo and Makhuwa (P30 Bantu languages). Linguistique et Languages Africaines 2. 43-75.

Halle, Morris \& Alec Marantz. 1993. Distributed Morphology and the pieces of inflection. In Kenneth Hale \& Samuel Jay Keyser (eds.), The view from Building 20. 111-176. Cambridge, MA: MIT Press.

Halle, Morris \& Alec Marantz. 1994. Some key features of Distributed Morphology. MIT working papers in linguistics 21. 275-288.

Hankamer, Jorge \& Line Mikkelsen. 2018. Structure, architecture, and blocking. Linguistic Inquiry 49(1). 61-84. https://doi.org/10.1162/LING_a_00266.

Höehn, Georg. 2015. Demonstratives and personal pronouns. Cambridge Occasional Papers in Linguistics 8:5. 84-105.

Kramer, Ruth. 2014. Gender in Amharic: A morphosyntactic approach to natural and grammatical gender. Language Sciences 43. 102-115. https://doi.org/10.1016/j.langSci.2013.10.004.

Kramer, Ruth. 2015. The Morphosyntax of Gender. Oxford: Oxford University Press.

Kramer, Ruth. 2016. A split analysis of plurality: Number in Amharic. Linguistic Inquiry 47. 527-559. https://doi.org/10.1162/LING_a_00220.

Kula, Nancy C. 2012. Nominal compounding and associative phrases in Bemba. In Matthias Brenzinger \& Anne-Maria Fehn (eds.), Proceedings of the 6th World Congress of African Linguistics (Cologne 2009). Cologne: Rüdiger Köppe. 431-441.

Marten, Lutz. 2010. The great Siswati locative shift. In Anne Breitbarth, Christopher Lucas, Sheila Watts \& David Willis (eds.), Continuity and Change in Grammar. 249-267. Amsterdam: John Benjamins.

Marten, Lutz. 2012. Agreement in locative phrases in Luganda. In Matthias Brenzinger \& Anne-Maria Fehn (eds.), Proceedings of the 6th World Congress of African Linguistics (Cologne 2009). Cologne: Rüdiger Köppe. 433-443.

Mathieu, Éric. 2012. Flavors of division. Linguistic Inquiry 43(4). 650-679. https://doi.org/10.1162/ling_a_00110.

Nunes, Jairo. 2004. Linearization of chains and sideward movement. Cambridge, MA: MIT Press.

Punske, Jeffrey \& Scott Jackson. 2017. The bifurcated nature of plural: Reconsidering 
evidence from English compounds. Proceedings of 43rd Annual Meeting of Berkeley Linguistics Society 43. 261-284.

Richards, Norvin. 2016. Contiguity theory. Cambridge, MA: The MIT Press.

Sato, Yosuke. 2010. Bare verbal nouns, idiomatization and incorporation in Japanese. Paper presented at Theoretical East Asian Linguistics 6, Peking University.

Wasow, Thomas, Geoffrey Nunberg \& Ivan Sag. 1984. Idioms: an interim report. In Shiro Hattori \& Kazuko Inoue (eds.), Proceedings of the 13th International Congress of Linguists. 102-115. The Hague: CIPL.

Zwicky, Arnold M. 1995. Exceptional degree markers: A puzzle in internal and external syntax. OSU Working Papers in Linguistics 47. 111-123. 